\title{
INTERPRETIVE SUMMARIES, JANUARY 2011
}

Toward the integration of expert knowledge and instrumental data to control food processes: Application to Camembert-type cheese ripening. By Sicard et al., page 1. Modeling the cheese ripening process remains a challenge because the process itself is a complex system. However, knowledge may be gathered from expert know-how. The aim of this study was to elicit and check the validity of expert knowledge to control Camembert cheese ripening. Expert knowledge was compared with microbiological, physico-chemical, and biochemical measurements during experimental ripening. A correlation of $76 \%$ was established between the microbiological, physico-chemical, and biochemical data and the sensory phases measured according to expert knowledge. In the future, expert knowledge may be integrated into food process models to build better decision-support systems that preserve organoleptic quality during the processes by linking them to phenomena at the microscopic level.

Characterization of high-milk-protein powders upon rehydration under various salt concentrations. By Hussain et al., page 14. Milk proteins are a valuable source of protein because they combine a high nutritional value and varied functional properties such as gelling, emulsification, and coagulation. However, the end user has to rehydrate the protein powder before use. The ionic environment ( $\mathrm{NaCl}$ and $\mathrm{CaCl}_{2}$ solutions) influenced rehydration and secondary structure of milk protein powders. High salt concentration strongly modified the protein backbone. From an industrial point of view, our project contributes data on the dynamics of hydration in connection with environment.

Fat composition of organic and conventional retail milk in northeast England. By Butler et al., page 24. Milk fat composition is influenced by management, especially feeding, of cows, and this study considers persistence of variation through the supply chain. In the United Kingdom, milk purchased in the summer or produced under organic management had higher concentrations of beneficial unsaturated fatty acids, including n-3 polyunsaturated fatty acids and conjugated linoleic acid. Organic milk can maintain essential fatty acid intake associated with a 30 to $50 \%$ reduction in total fat consumption. Year-to-year variation was also identified, possibly explained by changes in dairy feeding due to adverse weather, which could become more frequent as climates change.

Effect of glycation on sodium caseinate-stabilized emulsions obtained by ultrasound. By Corzo-Martinez et al., page 51. Dairy proteins, such as sodium caseinate (SC), are widely used in the food industry as functional ingredients because of their excellent nutritional value and versatile techno-functional properties. Nevertheless, the food industry is searching for procedures to obtain new ingredients with improved functional properties. High-intensity ultrasound (HIUS) is receiving attention as an alternative to conventional emulsification systems. In this context, this article explores the potential of HI-US as an emerging technique to produce fine-dispersion and long-timestable oil-in-water emulsions prepared with native and glycated SC. Results showed that the combination of early stage glycation of SC and HI-US could yield improved emulsions that could be used in a number of food applications.

Survey of the fatty acid composition of retail milk in the United States including regional and seasonal variations. By O'Donnell-Megaro et al., page 59. The fatty acid composition of retail milk was evaluated based on fluid milk samples obtained from 56 processing plants across the United States. Statistical differences among geographical regions and across seasons were identified for some fatty acids. However, without exception, differences were minor and overall results demonstrate that the milk fatty acid profile is remarkably consistent across geographic regions and seasons from the perspective of human dietary intake of milk fat.

The effect of bovine milk lactoferrin on human breast cancer cell lines. By Duarte et al., page 66. New opportunities for cancer prevention through changes in diet regimens can be developed from the increasing knowledge of the effects of food components on health. Lactoferrin, an iron-binding glycoprotein, decreased breast cancer cell viability and proliferation, increased levels of apoptosis, and decreased cancer cell migration.

Heat stress abatement during the dry period influences metabolic gene expression and improves immune status in the transition period of dairy cows. By do Amaral et al., page 86. The effect of heat stress (HT) abatement was evaluated during the dry period on metabolic gene expression and immune status. From dry-off until parturition, Holstein cows were exposed to HT or were actively cooled (CL). Cows exposed to CL had lower prolactin concentration in plasma and greater neutrophil phagocytosis and oxidative burst postpartum compared with HT cows. Cows exposed to CL had greater hepatic mRNA expression of prolactin receptor (PRL-R), suppressor of cytokine signaling-3 (SOCS-3), and caveolin-1 (CAV-1) compared with HT cows, suggesting that HT abate- 
ment during the entire dry period alters hepatic gene expression and improves immune status and subsequent milk production.

Restless behavior increases over time, but not with compressibility of the flooring surface, during forced standing at the feed bunk. By Krebs et al., page 9\%. This study evaluated how the type and compressibility of the flooring surface in front of the feed bunk influenced the behavioral response to $4 \mathrm{~h}$ of forced standing after morning milking. Two flooring types were compared: rubber and concrete. Rubber was tested at 3 levels of compressibility: 2, 4, and 35 times as compressible as concrete. Restless behavior increased over the $4 \mathrm{~h}$ of forced standing, but did not differ between the flooring materials tested. It is unclear if comfort did not differ between these options or if alterative methodology is required to detect such differences.

A retrospective study on the association between different lengths of the dry period and subclinical mastitis, milk yield, reproductive performance, and culling in Chilean dairy cows. By Pinedo et al., page 106. The objective was to determine the association between dry period length and subclinical mastitis, milk yield, reproductive performance, and risk of culling during the subsequent lactation of Chilean dairy cows. Results indicated that extended dry periods (143 to $250 \mathrm{~d}$ ) increased the odds of subclinical mastitis during early lactation and had a negative association with reproductive performance. Short (0 to $30 \mathrm{~d}$ ) and extended dry periods were negatively associated with early lactation and 305-d milk yield and were related to increased overall culling when compared with the reference dry period of 53 to $76 \mathrm{~d}$.

Characteristics of prolonged luteal phase identified by milk progesterone concentrations and its effects on reproductive performance in Holstein cows. By Ranasinghe et al., page 116. The incidence of prolonged luteal phase (PLP) in Holstein cows from 3 dairy herds ranged from 9.5 to $16.7 \%$. Higher parity, postpartum complications, and early commencement of luteal activity were associated with increased occurrence of PLP. Moreover, PLP adversely affected reproductive performance by reducing pregnancy rates and extending the interval from calving to conception.

Mastitis diagnostics: Quantitative PCR for Staphylococcus aureus genotype B in bulk tank milk. By Boss et al., page 128. Staphylococcus aureus genotype $\mathrm{B}$ is a pathogenic and contagious subtype that causes chronic bovine mastitis and thereby great economic loss in Swiss dairy herds. It can now be detected directly in bulk tank milk using a novel quantitative PCR-based assay. The method is highly specific and sensitive for this genotype. This novel assay is suitable for routine purposes and is expected to be an effective tool for minimizing Staphylococcus aureus genotype B in Swiss dairy herds

Antimicrobial activity of bovine $\beta$-lactoglobulin against mastitis-causing bacteria. By Chaneton et al., page 138. In spite of $\beta$-lactoglobulin being a profoundly studied molecule and the most abundant protein in bovine milk whey, its biological function is not thoroughly understood. In this work we present evidence that $\beta$-lactoglobulin possess antibacterial activity against the mastitis-causing agents Staphylococcus aureus and Streptococcus uberis but not against Escherichia coli. This spectrum of activity is, to a certain extent, complementary to that observed for bovine lactoferrin, a known antimicrobial protein present in milk. Our findings suggest that lactoferrin and $\beta$-lactoglobulin cooperate in mammary gland defense against bacterial infection.

Efficacy of carprofen on conception rates in lactating dairy cows after subcutaneous or intrauterine administration at the time of breeding. By Heuwieser et al., page 146. Uterine manipulation can have negative effects on embryonic survival caused by the release of prostaglandins. Treatment with nonsteroidal antiinflammatory drugs (NSAID) after embryo transfer increases pregnancy rates. We evaluated the effect of an NSAID on reproductive performance in lactating dairy cows when administered at the time of the first artificial insemination. The results demonstrate that a subcutaneous treatment with an NSAID does not have a positive effect, whereas an intrauterine treatment has a negative effect on reproductive performance.

Anaphylatoxin C5a-induced toll-like receptor 4 signaling in bovine neutrophils. By Stevens et al., page 152. During the periparturient period cows are more susceptible to the development of clinical mastitis which leads to reduced milk production and economic loss. In some cases mastitis can result in sepsis. During sepsis elevated concentrations of the anaphylatoxin C5a are produced. We analysed the effect of a high concentration of C5a on the toll-like receptor 4 (TLR4) pathway, which is involved in pathogen recognition. We show that C5a is able to interfere with the expression of TLR4 pathway genes and induces interleukin- 8 expression in neutrophils.

Selenomethionine increases proliferation and reduces apoptosis in bovine mammary epithelial cells under oxidative stress. By Miranda et al., page 165. Recent studies demonstrated that organic selenium supplementation increases milk production. It is still unclear how selenium itself may produce this effect. Oxidative damage is associated with increased 
epithelial cell death and decreased milk yield after peak lactation; therefore, we tested in vitro whether selenomethionine may affect apoptosis or cell proliferation by changing the antioxidant status of secretory cells. Selenomethionine reduced apoptosis and increased cell proliferation of primary bovine mammary epithelial cells under oxidative stress. This positive effect of selenium was independent of the decrease in intracellular concentration of $\mathrm{H}_{2} \mathrm{O}_{2}$.

Cow-specific treatment of clinical mastitis: An economic approach. By Steeneveld et al., page 174. In many countries, clinical mastitis cases of dairy cows are treated with a standard intramammary antimicrobial treatment. Several antimicrobial treatments are, however, available for clinical mastitis, differing in antimicrobial compound, route of application, duration, and costs. Because cow factors (e.g., parity, stage of lactation, and somatic cell count history) influence the probability of cure, it was expected that cow-specific treatment would be economically beneficial. Result of the current study show that although effectiveness of different antimicrobial treatments does vary between cows, differentiation of treatments for different clinical mastitis cases does not provide economic benefits.

Effects of differential supplementation of fatty acids during the peripartum and breeding periods of Holstein cows: I. Uterine and metabolic responses, reproduction, and lactation. By Silvestre et al., page 189. Feeding calcium salts of safflower oil, a linoleic acid rich supplement, during peripartum of dairy cows increased milk yield and caruncular n-6:n-3 fatty acid ratio. Following the transition period, feeding calcium salts of fat enriched in fish oil reduced pregnancy loss after first artificial insemination and increased pregnancy per insemination after the second insemination. This beneficial effect of feeding calcium salts of fish oil was augmented when calcium salts of safflower oil were fed previously in the transition period. Collectively, strategic supplementation of fatty acids according to physiological stage can increase production and reproduction of dairy cows.

Alternative programs to presynchronize estrous cycles in dairy cattle before a timed artificial insemination program. By Stevenson, page 205. Estrus was presynchronized before a timed artificial insemination (TAI) program, including variants of a Presynch protocol and 2 with progesterone. No treatment increased the percentage of cows having a corpus luteum (CL) and ovulating during the TAI program. Pregnancy rate was not different among treatments but decreased when progesterone was removed $3 \mathrm{~d}$ before initiating the TAI program. More cows having elevated progesterone and larger follicles $(>14 \mathrm{~mm})$ before the first gonadotropin-releasing hormone $(\mathrm{GnRH})$ of the
TAI program ovulated after the first $\mathrm{GnRH}$, whereas more cows with at least $1 \mathrm{CL}$ before prostaglandin $\mathrm{F}_{2 \alpha}$ and low progesterone before the second GnRH ovulated thereafter.

Effects of postbreeding gonadotropin treatments on conception rates of lactating dairy cows subjected to timed artificial insemination or embryo transfer in a tropical environment. By Vasconcelos et al., page 223. Embryo transfer (ET) and treatments to increase postbreeding circulating concentrations of progesterone are potential strategies to improve reproductive performance of the modern dairy cow. In these studies, treatment with gonadotropin-releasing hormone $(\mathrm{GnRH})$ or human chorionic gonadotropin (hCG) $7 \mathrm{~d}$ after induced ovulation increased conception in highproducing dairy cows submitted to timed ET, but not in those submitted to timed artificial insemination. Moreover, in cows treated with GnRH concurrently with ET, an additional treatment with GnRH $7 \mathrm{~d}$ after ET did not enhance conception. Use of ET associated with a concurrent injection of GnRH or hCG may improve reproductive efficiency of the modern dairy cow.

Process audits versus product quality monitoring of bulk milk. By Velthuis and van Asseldonk, page 235. To quantify the relation between dairy farm audits and milk quality monitoring, audit outcomes were compared with bulk milk test results. The analyzed data set comprised 64,373 audit outcomes on 26,953 dairy farms over a period of 6.5 years and all conducted lab tests of bulk milk samples. Bulk milk quality was more likely to be inferior if dairy farms were assessed negatively on specific audit aspects. However, the proportion of the total variance in milk test results explained by audits ranged between $4 \%$ and $13 \%$ (depending on the specific bulk milk test), showing that auditing dairy farms provides additional information, but has a limited association with the outcome of a product quality control program.

Diagnosing intramammary infections: Evaluation of definitions based on a single milk sample. By Dohoo et al., page 250. This study used 2 large data sets of culture results to evaluate a number of definitions (sets of criteria) for classifying a quarter as having or not having an intramammary infection (IMI) by comparing the results from a single culture to a gold standard diagnosis based on a set of 3 milk samples. The estimates of sensitivity (ability of a definition to detect IMI) were very low, particularly for any definition that required anything more that the isolation of a single colony from $0.01 \mathrm{~mL}$ of milk). The estimates of specificity (ability of a definition to correctly classify noninfected quarters) were generally quite high except for coagulase-negative staphylococci infections when the most liberal definition (isolation of a single colony) 
was used. This information is important for correct interpretation of diagnostic test results.

Selenium levels in cows fed pasture and concentrates or a total mixed ration and supplemented with selenized yeast to produce milk with supra-nutritional selenium concentrations. By Stockdale et al., page 262. Bovine milk containing elevated concentrations of selenium provides a rich nutritional source of this essential element for meeting daily nutritional requirements or providing health benefits in humans with low immune function or at risk of cancer. Pasture-fed or total mixed ration-fed dairy cows provided with organic selenium supplements produced milk with high and consistent concentrations of selenium, and the response was not affected by diet. Therefore, feeding systems can be developed in which milk is produced with predictably consistent selenium concentrations to enable processing into selenium-rich products regardless of the diet fed to the cows.

Dairy cattle prefer shade over sprinklers: Effects on behavior and physiology. By Schütz et al., page 273. Shade is readily used by cattle in warm weather, but less is known about voluntarily use of sprinklers. We evaluated preference for sprinklers, shade, or ambient conditions (no cooling). Cows preferred shade over sprinklers and ambient conditions. The preference for shade increased with warm weather, but was not influenced by the distance walked (2.0 or $0.3 \mathrm{~km}$ ) before testing. Sprinklers were more efficient in reducing respiration rate, surface temperature, and insect avoidance behaviors compared with shade and ambient conditions. Dairy cattle prefer to use shade in summer despite sprinklers being more efficient in reducing heat load.

Determination of ceftiofur derivatives in serum, endometrial tissue, and lochia in puerperal dairy cows after subcutaneous administration of ceftiofur crystalline free acid. By Witte et al., page 284. Puerperal uterine infections such as metritis and endometritis are common problems in high-producing dairy cows and are often associated with decreased reproductive performance. The treatment of choice is a systemic injection of antibiotics to reduce the effect of uterine infections on fertility. Efficacy of an antibiotic requires concentrations above the minimum inhibitory concentrations of relevant pathogens. Our results demonstrate that concentrations of ceftiofur derivatives in serum, endometrial tissue, and lochia of puerperal dairy cows after a single subcutaneous administration of ceftiofur crystalline free acid at the base of the ear remained above the reported minimum inhibitory concentration of relevant pathogens over a 7 -d period.
Metagenomic analysis of the uterine bacterial microbiota in healthy and metritic postpartum dairy cows. By Santos et al., page 291. Metritis, one of the most important reproductive disorders in dairy cows, is caused by uterine bacterial contamination after parturition. Traditional cultural methods have shown that a variety of aerobic and anaerobic bacteria are present in the infected uterus and are likely to cause dairy cattle metritis. However, the vast uncultured fraction of the uterine microbiota has received no attention to date. In this study, we used a combination of culture-independent methods to describe and compare the bacterial composition in the uteri of healthy and metritic Holstein postpartum dairy cows. Fusobacteria was the dominant group in clone libraries from metritic dairy cows, and Gammaproteobacteria were more dominant in those libraries from healthy dairy cows.

\section{Somatotropic axis and concentrate supplementa-} tion in grazing dairy cows of genetically diverse origin. By Grala et al., page 303. Transcription of somatotropic axis components was not affected by feed supplementation in grazing dairy cows, irrespective of their genetic origin. However, molecular lipogenic factors in liver tissue were upregulated in supplemented cows and in those of New Zealand origin. Circulating concentrations of growth hormone were lower in supplemented cows until wk 4 postpartum, at which point concentrations in unsupplemented cows started to decline. Furthermore, blood insulin concentrations were increased in supplemented New Zealand cows but not in North American cows after wk 7 postpartum, indicating genetic differences in physiological responses to supplementation.

Short communication: Effects of trans fatty acids on markers of inflammation in bovine mammary epithelial cells. By Rezamand and McGuire, page 316. Inflammation is a common part of many pathophysiological conditions such as obesity and mastitis. Trans fatty acids (tFA) are unsaturated fatty acids containing one or more double bonds in the trans configuration. Some tFA can modify production of immune and inflammatory mediators. The objective was to elucidate the relationship between selected tFA and inflammatory status in cell culture experiments using bovine mammary cells. Elaidic and linoleidic acids both altered expression of inflammatory markers at the transcription level, suggesting the potential to alter the inflammatory state of the mammary gland through dietary means.

Milk urea concentration as an indicator of ammonia emission from dairy cow barn under restricted grazing. By van Duinkerken et al., page 321. 
Emission of ammonia from dairy cow barns is a primary cause of environmental eutrophication and acidification. In an experiment with 52 Holstein-Friesian cows, diets were adjusted to achieve bulk milk urea contents of 15 , 35 , and $55 \mathrm{mg} / 100 \mathrm{~g}$. Ammonia emission was strongly influenced by diet. Bulk milk urea content was shown to be a useful and practical tool to predict ammonia emission reduction from dairy cow barns.

A prospective study of calf factors affecting first-lactation and lifetime milk production and age of cows when removed from the herd. By Heinrichs and Heinrichs, page 336. This study investigated possible effects of calf management during the first 16 wk of life on first lactation and lifetime milk production and on age when animals were removed from production. Results showed that delivery score, weaning dry matter intake, days of illness before 4 mo, days treated before $4 \mathrm{mo}$, and body weight at calving affected first-lactation production of Holsteins. Delivery score and grain intake at a young age affected lifetime milk production.

Effect of early feed type exposure on diet selection behavior of dairy calves. By Miller-Cushon and DeVries, page 342. The objective of this study was to determine how early exposure to different feed types (concentrate or hay) affects diet selection behavior (sorting) of dairy calves once fed a mixed ration of these feeds after weaning off milk. Immediately after weaning, calves sorted the mixed ration in favor of the familiar feed type and against the novel feed type. However, after 4 wk consuming a common mixed ration, sorting was similar between treatments, with all calves sorting for concentrate and against hay. These results suggest that early feed type exposure may affect diet selection initially postweaning, but may not have a lasting influence on feed sorting behavior.

Population structure of rumen Escherichia coli associated with subacute ruminal acidosis (SARA) in dairy cattle. By Khafipour et al., page 351. Rumen Escherichia coli populations were examined in dairy cows induced with subacute ruminal acidosis (SARA) by feeding a grain-pellet or an alfalfa-pellet (API) diet. Grain pellet-induced SARA contained a subset of E. coli with a distinctly different genetic composition than other groups. The animals fed the grain pellet diet had $E$. coli carrying $\mathrm{crl}$ virulence genes that are potent inducers of the immune system.

Differential expression of genes in adipose tissue of first-lactation dairy cattle. By Sumner-Thomson et al., page 361. Using transcriptome gene chip array analyses, several genes were determined to change expression in adipose tissue of dairy cattle in early lactation. Many of these genes control synthesis, transport, and metabolism of fatty acids in adipose tissue. Some were related to milk production and body fat changes, and several others were involved in cell cycle control, immunity, and inflammation. These results confirm some key metabolic control points that can be targeted for further research to define the genotypic and phenotypic control of metabolic efficiency in dairy animals.

Exclusion of dietary sodium bicarbonate from a wheat-based diet: Effects on milk production and ruminal fermentation. By Doepel and Hayirli, page 370. This experiment was conducted to evaluate the effects of excluding sodium bicarbonate from a diet with $20 \%$ steam-rolled wheat grain on performance, rumen fermentation, and whole-tract digestibility of nutrients of lactating dairy cows. Response variables were not affected by removal of sodium bicarbonate from the diet, suggesting that lactating cows can safely be fed up to $20 \%$ steam-rolled wheat on a dry matter basis without necessitating buffer supplementation, as long as the diet contains sufficient fiber.

Effect of wheat middlings-based total mixed ration on milk production and composition responses of lactating dairy ewes. By Tufarelli and Laudadio, page 376. The effect of feeding a pelleted total mixed ration containing wheat middlings (WM) from durum wheat, as corn grain substitute on milk yield and composition, was measured in crossbred lactating ewes. The WM diet increased milk fat percentage and yield but had no effect on milk yield, protein, lactose, and clotting properties compared with the control diet. Our findings indicate that feeding 50\% WM in a lactation diet supported milking performance similarly to that of ewes fed a corn-based diet. The results could be applied in countries where corn cultivation is adversely affected by high costs of production.

Effects of lauric and myristic acids on ruminal fermentation, production, and milk fatty acid composition in lactating dairy cows. By Hristov et al., page 382. This experiment was conducted to evaluate the antimethanogenic effect of lauric or myristic acids, major fatty acids in coconut oil, in lactating dairy cows. Lauric acid had an overall suppressing effect on ruminal fermentation and dramatically reduced protozoal counts. Neither lauric nor myristic acids, however, affected methane production in the rumen. Lauric acid also depressed feed intake and milk production and caused milk fat depression, most likely resulting from increased ruminal production of antilipogenic fatty acids such as conjugated linoleic acid isomers.

Interactions of monensin with dietary fat and carbohydrate components on ruminal fermentation and production responses by dairy cows. By Mathew et al., page 396. Milk fat concentration 
and yield is reflective of animal health and affects the amount paid to the dairy producer. This study investigated the effects of feeding monensin in diets differing in starch availability (ground or steam-flaked corn), effective fiber (long or short alfalfa hay), and fat. Although monensin caused milk fat depression, addition of fat did not exacerbate this occurrence. The steam-flaked corn diets resulted in greater milk fat depression with short than with long alfalfa hay. Formulation of diets to improve feed efficiency must also take into account the degradability of the starch and particle size of forage.

Sodium dodecyl sulfate reduces bacterial contamination in goat colostrum without negative effects on immune passive transfer in goat kids. By Morales-delaNuez et al., page 410. Ruminant farmers may need to feed colostrum by hand and usually they must reduce the bacterial content of the colostrum. Although pasteurization is the most commonly used practice to reduce the bacterial content of colostrum, it partially destroys immunoglobulins. The present paper details a new possibility for reducing the bacterial content of colostrum that does not damage the beneficial immunoglobulins it contains. The approach, in which 9 parts of colostrum are mixed with 1 part $10 \%$ SDS for $10 \mathrm{~min}$ at $36^{\circ} \mathrm{C}$, is simple and reduces the bacterial content to a similar degree as pasteurization.

Effect of rumen-undegradable protein supplementation and fresh forage composition on nitrogen utilization of dairy ewes. By Mikolayunas et al., page 416. Dairy ewes consuming fresh forage indoors tended to increase milk production when provided a source of rumen-undegradable protein. When ewes were consuming fresh forage indoors and on pasture, increasing the percentage of dietary alfalfa and decreasing the percentage of dietary orchardgrass increased dry matter intake, milk and milk protein yields, and nitrogen excretion in urine. Milk nitrogen efficiency, estimated by milk nitrogen excretion divided by dietary nitrogen intake, was greater in ewes consuming only orchardgrass compared with that in ewes fed diets containing alfalfa. Dairy sheep producers can increase milk yield of grazing ewes by maintaining pastures with $50 \%$ alfalfa

Technical note: Evaluation of a system for monitoring rumination in heifers and calves. By Burfeind et al., page 426. A commercially available electronic rumination monitoring system provides a reasonable measure of rumination time in dairy cows, but has not been validated for young cattle. The overall objective of this study was to validate this rumination monitoring system in heifers and calves. Our results indicate that the system provides accurate measures of rumination behavior in Holstein heifers from the age of $9 \mathrm{mo}$, but is less reliable for younger calves.
Effect of enlarging the reference population with (un)genotyped animals on the accuracy of genomic selection in dairy cattle. By Pszczola et al., page 431. Genotyping a large number of animals using high-density single nucleotide polymorphism marker arrays is still expensive. This study investigated the influence of enlarging the reference population, either with genotyped animals or individuals with predicted genotypes, on the accuracy of genomic estimated breeding values. Inclusion of ungenotyped animals in the reference populations did not increase accuracy unless the heritability was low.

Lactation curve models for estimating gene effects over a timeline. By Strucken et al., page 442. Effects of genes are commonly estimated by using random regression models based on test-day data and give only a general gene effect. Alternatively, lactation curve models can be used to estimate biological and environmental effects, or to predict missing test-day data and perform breeding value estimation. This study combines lactation curve models and estimation of gene effects to investigate changes in gene effects during the lactation cycle. The well-characterized DGAT1 gene with known effects on milk yield, and milk fat and protein production was chosen to test this new approach in a Holstein-Friesian dairy cattle population. We show that the known genotype effect of the DGAT1 gene with a low milk yield and high fat content become apparent only after lactation d 40. During the first weeks of the lactation, genotype effects might even be opposite of those observed for later lactation weeks. Furthermore, the lactation stage in which effects are expressed is different for each trait.

Estimation of genetic parameters for measures of calf survival in a population of Holstein heifer calves from a heifer-raising facility in New York State. By Henderson et al., page 461. Calf survival is a major concern for dairy producers. Premature death has severe economic consequences and is a welfare concern. Genetic variation exists among sires for survival of calves after weaning through the growing period. Significant associations exist among genetic evaluations for survival traits and routinely evaluated traits in Canada and the United States, in particular with conformation body traits, somatic cell score, fertility, and longevity.

Genetic analysis of mastitis data with different models. By Hinrichs et al., page 471. Genetic improvement of functional traits (e.g. health and fertility traits) is one of the most important points in dairy cattle breeding programs, because these traits have an unfavorable genetic correlation to milk production traits. In this study, different threshold models and mastitis trait definitions were considered. The heritability estimates 
for liability to clinical mastitis varied from 0.08 to 0.15 and repeatability estimates varied between 0.16 and 0.70 . The rank correlations between breeding values from different data sets ranged from 0.40 to 0.96 .

Genome-wide association study for calving traits in Danish and Swedish Holstein cattle. By Sahana et al., page 479. A total of 22 quantitative trait loci (QTL) were detected on 19 chromosomes for direct and maternal calving traits in cattle using a genomewide association study. Calving performance is affected by the genotypes of both the calf (direct effect) and the dam (maternal effect). The identification and localization of these QTL in small chromosomal regions will aid in the selection of animals with improved calving traits and facilitate the identification of the candidate genes underlying these QTL.

Genetic effects of heat stress on milk yield of Thai Holstein crossbreds. By Boonkum et al., page 48\%. The effect of heat stress on Thai Holstein crossbreds was studied using test-day milk records for the first 3 parities. The decline of milk yield under heat stress increased with parity and percentage of Holstein genes. The genetic component of heat stress quadrupled from first to third parity but was small compared with that of US cows.

A comparison of dairy cattle breeding designs that use genomic selection. By Lillehammer et al., page 493. Two breeding designs that use genomic selection were compared with a conventional progenytesting breeding scheme. Omitting the progeny test and use of genomic breeding values to select elite sires at younger age increased both genetic gain and the rate of inbreeding. By selecting more sires, increased genetic gain could be achieved without increasing the rate of inbreeding. Using genomic selection to preselect young bulls before progeny testing gave a smaller increase in genetic gain and rate of inbreeding. Hence, genomic selection can increase the efficiency of dairy cattle breeding programs.

Short communication: Jersey $\times$ Holstein crossbreds compared with pure Holsteins for production, mastitis, and body measurements during the first 3 lactations. By Heins et al., page 501. Jersey $\times$ Holstein crossbred cows were not significantly different from pure Holstein cows for fat plus protein production during first lactation, but had lower fat plus protein production than did pure Holstein cows during second and third lactations. For lifetime milk, fat, and protein production to 1,220 d after first calving, Jersey $\times$ Holstein crossbred cows were not significantly different from pure Holstein cows. Jersey $\times$ Holstein cows were not significantly different from pure Holstein cows for somatic cell score and clinical mastitis dur- ing first and second lactations; however, the crossbred cows tended to have higher somatic cell score than did pure Holstein cows but significantly lower clinical mastitis during third lactation. Finally, Jersey $\times$ Holstein crossbred cows had significantly less hip height, smaller heart girth, less udder clearance, and greater distance between the front teats than did pure Holstein cows during the first 3 lactations.

Short communication: Interaction of energy balance, feed efficiency, early lactation health events, and fertility in first-lactation Holstein, Jersey, and reciprocal $\mathbf{F}_{1}$ crossbred cows. By Olson et al., page 50\%. Early lactation energy balance and disease were investigated in 140 first-lactation cows in the Holstein-Jersey crossbreeding project at Virginia Tech (Blacksburg). Probability of an incidence of mastitis was lower in Holsteins than in the crossbreds and Jerseys. Cows that had an incidence of ketosis had a more negative energy balance at wk 15 in lactation. Energy intake was lower for cows with an incidence of displaced abomasum or mastitis.

Short communication: Genetic parameters of milking temperament and milking speed in Canadian Holsteins. By Sewalem et al., page 512. The objectives of this study were to estimate genetic parameters of milking temperament (MT) and milking speed (MS) in Canadian Holsteins and to examine associations of bull proofs of MT and MS with other economically important traits. Heritability estimates were 0.128 and 0.139 for MT and MS, respectively. The genetic correlation between milking temperament and milking speed was 0.247 . This suggests that cows with a calm temperament during milking let down their milk quicker. Bull proof correlations of MT and MS with other economically important traits showed significant but low relationships with a wide range of traits such as production, reproduction, conformation, and auxiliary traits.

The impact of land fragmentation on milk production. By del Corral et al., page 51\%. Land fragmentation is a feature common in many countries around the world and its effect is usually assumed to be negative. Very often, policy makers have tried to attenuate the degree of land fragmentation by implementing some sort of land consolidation process. This study evaluates the effect of land fragmentation on the efficiency and economic performance of dairy production. To reach our goal we used a sample of Spanish dairy farms located in a region where land is highly fragmented. The results show that reducing the number of plots will induce an increase in milk production.

Viable cell yield from active dry yeast products and effects of storage temperature and diluent 
on yeast cell viability. By Sullivan and Bradford, page 526. Yeast viability was measured in samples from commercially available active dry yeast products. Samples were subjected to warm $\left(40^{\circ} \mathrm{C}\right)$ storage temperature for $3 \mathrm{mo}$, and colony-forming units were evaluated after 1,2 , and 3 mo of storage. Samples were also mixed with ground corn or a vitamin/trace mineral pack and subjected to warm or ambient $\left(22^{\circ} \mathrm{C}\right)$ temperature storage for 2 wk. The products had highly variable viable yeast counts, and only one product consistently met its product guarantee. Cell viability decreased in warmer environments but at a slower rate when products were stored in a vitamin/trace mineral mix than in ground corn. 